\title{
COMPONENTES DEL ENREDO EN UNA COMEDIA DE CAPA Y ESPADA DE ROJAS ZORRILLA: PRIMERO ES LA HONRA QUE EL GUSTO ${ }^{1}$
}

\author{
Alberto GutiérRez GIL \\ Universidad de Castilla-La Mancha
}

Resulta innegable el especial talento cómico de Rojas y su capacidad para construir un enredo mucho más complejo que el que podemos encontrar en la producción lopesca. De hecho, lo que hace sobresalir al autor toledano frente a otros dramaturgos contemporáneos es su valentía a la hora de presentar nuevos caminos en la construcción de la trama argumental de la comedia, tejiendo enredos cada vez más ingeniosos y buscando la sorpresa del auditorio por medio de nuevas situaciones cómicas en las que sumergir a los personajes.

\footnotetext{
1 Este trabajo forma parte de los proyectos de investigación CSD2009-00033 (Consolider: «Patrimonio teatral clásico español: textos e instrumentos de investigación») y FFI2011-25040 («Estudio y valoración final del teatro de Rojas Zorrilla»), y está realizado al amparo del Programa de Formación de Profesorado Universitario (FPU) del Ministerio de Ciencia e Innovación.
} 
Tal y como nos muestran numerosos estudiosos de la obra de Rojas ${ }^{2}$, su teatro destaca y se define por la reiteración en el uso de diferentes técnicas de enredo que cimientan la trama y complican el argumento. Raymond $\mathrm{MacCurdy}^{3}$, insigne conocedor y editor de la obra de Rojas Zorrilla, ya se hacía eco de la importancia de la generación calderoniana como origen del refinamiento y embellecimiento de la estructura y la unidad de la comedia, y posicionaba a nuestro autor delante de Calderón de la Barca en el desarrollo de estas herramientas compositivas debido a su buen instinto literario y su intensa conexión con el público.

Sin embargo, no todo han sido halagos para Rojas y sus compañeros de generación. Ann L. Mackenzie, por ejemplo, hace referencia a la falta de originalidad en las composiciones de estos dramaturgos debido a un convencionalismo desmedido en el uso de los mecanismos del enredo que desemboca en la corrupción de muchas de sus comedias: «Incluso los mejores escritores del ciclo calderoniano, o sea, Rojas, Moreto y Cubillo, produjeron algunas comedias de enredo estropeadas por un convencionalismo insistente y excesivo» ${ }^{4}$.

En este saco de «obras con tara» encontramos a Primero es la honra que el gusto. Tanto MacCurdy como Mackenzie consideran que la excesiva utilización de recursos del enredo ha abocado a la pervivencia, o más bien a la subsistencia, de esta comedia de capa y espada como un producto bastante mediocre dentro del corpus cómico de nuestro autor.

Más allá de estos análisis superficiales de Primero es la honra que el gusto, demostraremos cómo, a pesar de utilizar los mecanismos del enredo de manera convencional, estamos ante una interesante comedia de capa y espada en la que cada uno de ellos adquiere un significado en sí mismo.

Como se puede comprobar en el título del trabajo, hablamos de componentes del enredo y no de simples mecanismos o recursos. En un principio nuestra intención era presentar los diferentes recursos de los que Rojas se vale en esta comedia para aderezar la acción, pero nos dimos cuenta de que nos dejábamos una pieza fundamental en el

2 I. Arellano, Historia del teatro español del siglo XVII, Madrid, Cátedra, 1995, pp. 551-552; R. González Cañal, «Rojas Zorrilla», en Javier Huerta Calvo (dir.), Historia del teatro español. Vol. 1, Madrid, Gredos, 2003, p. 1155; V. Brancatelli, «El conflicto dramático en el teatro de Francisco de Rojas Zorrilla», en Felipe B. Pedraza Jiménez, Rafael González Cañal y Elena E. Marcello (eds.), Rojas Zorrilla en su IV centenario. Congreso internacional (Toledo, 4-7 de octubre de 2007), Cuenca, Universidad de Castilla-La Mancha, 2008, p. 527; M. Rodríguez Cáceres, «Perfil biográfico y literario de Francisco de Rojas Zorrilla», Boletín de la Compañía Nacional de Teatro Clásico, 40 (1999), p. 3.

3 R. MacCurdy, Francisco de Rojas Zorrilla, Nueva York, Twayne, 1968.

${ }^{4}$ A. L. Mackenzie, La escuela de Calderón: estudio e investigación, Liverpool, Liverpool University Press, 1993, p. 83. 
desarrollo del enredo y, por tanto, de la comedia: la criada. Así, además de engranajes como la reducción del tiempo y el espacio, la ocultación, la confusión de identidades o las escenas nocturnas, presentaremos otros elementos difícilmente clasificables que funcionan como andamiaje o soporte sobre el que se sustentan los mecanismos citados: la voluntad de la criada para enmarañar situaciones y los celos que galanes y damas albergan.

Obviaremos en este trabajo el análisis del amor y del honor dentro de la trama argumental, pues, dejando de lado opiniones que los distinguen como unos elementos más del enredo ${ }^{5}$, seguimos la línea abierta por el sector de la crítica que considera que estamos ante los dos temas que articulan cualquier comedia de capa y espada y, por los cuales, surgen los demás elementos estructurales.

\section{FLORA: «QUINTAESENCIA DEL ENREDO»}

«La quinta esencia / del enredo es la Florilla» (vv. 1250-1251) . De esta manera describe Pepino, gracioso de la obra, a la criada, Flora. Esta juega un papel de vital importancia en el desarrollo del enredo en la comedia y, como podemos ver en estos dos versos, destaca la maestría y el refinamiento (de ahí el apelativo de «quintaesencia») con los que Flora lleva a cabo su rol.

Gracioso y criada se han consolidado en la comedia nueva como unión humorística que salpimienta las comedias de capa y espada y, en la producción trágica, permite pequeños momentos de distensión en el desarrollo funesto de la acción. Raymond MacCurdy ${ }^{7}$ destaca la importancia del gracioso en las obras de Rojas, llegando a afianzarse como personaje principal de las tramas secundarias e, incluso, de la intriga central de la obra. De acuerdo se muestra Brancatelli ${ }^{8}$, que destaca a esta pareja dramática como motor de la comicidad. Sin embargo, deja en un segundo plano a las criadas, pues «no se revelarán importantes a la hora de lograr el desenlace: el autor las usa, más que nada, para informar de los hechos al público y a los personajes y como confidentes de las mujeres».

5 D. Símini, "El amor en Rojas: ¿sentimiento o adorno de la acción?", en Felipe B. Pedraza Jiménez, Rafael González Cañal y Elena E. Marcello (eds.), Rojas Zorrilla en su IV centenario. Congreso internacional (Toledo, 4-7 de octubre de 2007), Cuenca, Universidad de Castilla-La Mancha, 2008, p. 439.

6 Todas las citas extraídas de la comedia proceden de mi edición de Primero es la honra que el gusto, realizada como trabajo de investigación para la obtención del Diploma de Estudios Avanzados. Aparecerá publicada en un futuro en las Obras completas de Francisco de Rojas Zorrilla, sumándose a la labor de edición llevada a cabo desde el Instituto Almagro de teatro clásico.

7 R. MacCurdy, op. cit., 1968, p. 139.

8 V. Brancatelli, op. cit., 2008, p. 532. 
Hacer una generalización de tal calibre lleva aparejado el peligro de olvidarse de algunos ejemplos que pueden contradecir tal afirmación. En el caso de Primero es la honra que el gusto nos topamos con una criada que, no solamente tiene peso en el desarrollo de la acción, sino que se convierte en la urdidora principal del enredo, dejando en un segundo plano a Pepino, que juega un papel más ornamental basado en reiterados gracejos con los que Rojas muestra su maestría lingüística.

Felipe Pedraza ${ }^{9}$ ya destacaba a Flora dentro del conjunto de graciosas creadas por Rojas como la «suprema tracista» de su comedia, como una alcahueta que se acerca, o más bien conquista, el papel del gracioso. Teresa Julio, en su importante trabajo en torno a las criadas de Rojas Zorrilla ${ }^{10}$, sitúa a Flora dentro del grupo de las «criadas activas», aquellas que intervienen directamente en la acción y modifican el transcurso de los acontecimientos. Junto con Beatriz, de Donde hay agravios no hay celos, Flora es considerada una de las criadas activas por excelencia, pues es una enredadora nata con una gran facilidad de palabra y un fuerte poder de convicción. Dentro de este grupo tenemos también otros ejemplos que nos llevan a El más impropio verdugo (Laura), Los bandos de Verona (Esperanza) o Casarse por vengarse (Silvia), casos que quedarían excluidos si seguimos la línea de Brancatelli.

A pesar de que la obediencia a la dama es una de las funciones básicas de las criadas $^{11}$, en Primero es la honra que el gusto tenemos a una asistenta más preocupada en enredar la trama con el fin de conseguir recompensa material de los galanes y las damas. A lo largo de toda la obra, Flora participa de los amores y desamores de don Juan y Leonor con el fin de conseguir algo a cambio. Ya al comienzo de la obra obtiene un diamante por hacer creer a don Juan que ha entregado un papel a Leonor, suceso que no ha ocurrido:

Este diamante ya veo,

Flora, que es inferior paga,

no la deuda satisfaga,

acredite mi deseo. (vv. 33-36)

Inmediatamente después de cerciorarse de que ha obtenido su recompensa, en un aparte Flora se proclama la principal culpable del enmarañamiento de la red que une a los personajes implicados en el juego amoroso:

9 F. B. Pedraza Jiménez, «Las graciosas de Rojas Zorrilla», en Estudios sobre Rojas Zorrilla, Cuenca, Universidad de Castilla-La Mancha, 2007, pp. 71-86.

10 T. Julio, «Lo que son criadas: hacia una taxonomía del tipo cómico en Rojas Zorrilla», en Luciano García Lorenzo (ed.), La criada en el teatro español del Siglo de Oro, Madrid, Fundamentos, 2008, pp. 141165.

11 J. de José Prades, Teoría sobre los personajes de la comedia nueva, en cinco dramaturgos, Madrid, CSIC, 1963, pp. 125-126. 
(Buenos mis enredos van, Aparte.

la trampa ha sido cruel,

ni a Leonor di tal papel,

ni conoce a tal don Juan.) (vv. 41-44)

Y más aún, en un juego con el público, se propone como ejemplo de perfecta alcahueta, pues las mentiras que cuenta a damas y galanes le reportan numerosos beneficios:

(Toda alcahueta se ajuste

a imitar mi proceder,

que a un galán se ha de vender

a diamante cada embuste.) (vv. 45-48)

En la segunda jornada volvemos a encontrarnos a Flora aparentemente ayudando a don Juan a conquistar a Leonor. Tiene una carta de su ama en la que insta al galán a encontrarse con ella por la noche. Bien sabe Flora que la intención de Leonor es aclarar al caballero su inclinación por don Félix, pero en el juego de engaños que mantiene continúa haciendo albergar esperanzas a don Juan, de lo que obtiene como recompensa una cadena:

$\begin{array}{ll}\text { Don Juan. } & \text { Toma esta cadena, sea } \\ & \text { no paga sino señal } \\ & \text { de mi afecto, y dame, Flora, } \\ & \text { ese tesoro en que está } \\ & \text { cifrada de mi deseo } \\ & \text { la mayor felicidad. } \\ \text { FLORA. } & \text { Admito el trueque. (Si medio } \\ & \text { pliego de papel, no más, } \\ \text { paga así un amante, ¿a cómo } \\ \text { cada resma le saldrá?) (vv. 863-872) }\end{array}$

De nuevo se mofa en un aparte de la credulidad del galán:

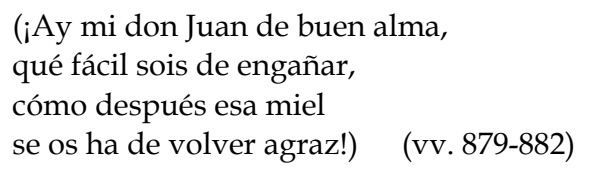

A lo largo de toda la comedia, Flora juega con los intereses de don Juan y los de su ama, Leonor, con el fin de conseguir estas pequeñas retribuciones. De esta manera, hasta el desenlace de la historia complica los lazos que unen el trío amoroso compuesto por Leonor, don Juan y don Félix, convirtiéndose así en el verdadero motor del enredo.

Tal naturaleza no pasa desapercibida para Pepino pues, perteneciente al mismo extracto social, comparte con ella la inclinación al juego de engaños y el interés por las riquezas materiales. Así, en dos ocasiones hace referencia a la pericia de la criada 
para enredar la situación. En la primera de ellas Pepino alaba, a la vez que recrimina, la conducta de Flora, destacando su malicia y su interés por el dinero:

$$
\begin{aligned}
& \text { Taimada protoalcahueta, } \\
& \text { que sin duda es Satanás } \\
& \text { tu catedrático en esta } \\
& \text { doctrina de alcahuetear; } \\
& \text { de las bolsas el ce ce, } \\
& \text { de los chismes el ziszás, } \\
& \text { cocinera de embelecos } \\
& \text { que con su pimienta y sal } \\
& \text { los guisas cual digan beatas; }
\end{aligned}
$$

La segunda le atañe especialmente pues, tras irrumpir en casa de Leonor ante la mirada atónita de don Rodrigo (padre de la dama), es Flora quien salva de la situación al gracioso mediante la creación de una nueva identidad para él. Una vez se cree a salvo, Pepino loa en un aparte la destreza de su compañera:

$$
\begin{array}{ll}
\text { (La quintaesencia } & \text { Aparte. } \\
\text { del enredo es la Florilla. } & \\
\text { ¡Mal año, cómo las pega!) } & \text { (vv. 1250-1252) }
\end{array}
$$

Y no solo Pepino se da cuenta de la importancia de las acciones de Flora en el devenir de la acción, sino que el propio don Juan reconoce el valor que las criadas tienen para conseguir buenos resultados en el juego del galanteo amoroso: «Quien las criadas granjea, / consigue un medio importante» (vv. 61-62).

A través de lo expuesto en este apartado, queda claro el peso de Flora como agente activo en el enredo en el que, como marionetas, se ven inmersos los personajes principales. Su pericia y su gracejo lingüístico la hacen destacar de entre el conjunto de criadas del corpus dramático de Rojas a la vez que la posicionan como uno de los personajes más importantes dentro del dramatis personae de la obra.

\section{REDUCCIÓN DEL TIEMPO Y EL ESPACIO}

Uno de los factores clave para comprender cómo se desarrolla el enredo en la comedia es la reducción del tiempo y el espacio dramático. En el caso de Rojas es significativo cómo la reducción del número de personajes lleva aparejada la disminución de los espacios en los que se desenvuelve la acción. González Cañal ${ }^{12}$

\footnotetext{
12 R. González Cañal, «El espacio escénico en las comedias de capa y espada de Rojas Zorrilla», en Escenografía y escenificación en el teatro español del Siglo de Oro. Actas del II Curso sobre teoría y práctica del teatro, Granada, Universidad de Granada, 2005, pp. 169-199; y «Recursos espaciales del enredo en Rojas Zorrilla», en Felipe B. Pedraza Jiménez, Rafael González Cañal y Gemma Gómez Rubio (eds.), Espacio, tiempo y género en la comedia española. Actas de las II Jornadas de teatro clásico. Toledo, 14, 15 y 16 de noviembre de 2003, Almagro, Universidad de Castilla-la Mancha, 2005, pp. 171-192.
} 
o Pastor Comín ${ }^{13}$ presentan numerosos ejemplos en torno a las comedias de capa y espada del autor toledano y demuestran cómo esta concentración espacial y temporal es uno de los factores determinantes del enredo, pues conllevan un juego artificioso de encuentros, confusión de identidades o escondites que, junto con los abundantes apartes, sustentan la intriga y alimentan la comicidad.

La acción se estructura en torno a tres espacios domésticos: las casas de don Juan, de don Félix y de Leonor. Tal y como ocurre en otras comedias de capa y espada, el enredo suele desarrollarse en el domicilio de la dama y, por tanto, a excepción de la primera jornada en la que la acción se sitúa principalmente en casa de don Félix, es la casa de Leonor el escenario de todo el juego dramático de ocultación y juegos de identidad.

La llegada de don Rodrigo, la aparición de un galán o de una dama o, simplemente, la obtención de información valiosa, llevan a los personajes a utilizar las estancias contiguas de la casa a un ritmo casi vodevilesco, en una sucesión elevada de escenas que contribuye al aligeramiento del ritmo dramático y, consecuentemente, al enredo. Y más llamativo es este hecho si tenemos en cuenta que estamos ante una comedia muy breve, de la que conservamos solamente 2022 versos.

Hemos de tener en cuenta, además del espacio físico de la historia, los diferentes espacios dramáticos que los personajes configuran dentro del escenario, lo que Javier Rubiera denomina «espacio lúdico» ${ }^{14}$ y que se identifican con acotaciones como «al paño», «hablan en secreto» o «hablan a coros». Es un recurso a través del cual se muestra sobre un mismo espacio escénico a varios grupos de actores que representan escenas simultáneas, es decir, se produce una escena múltiple que divide al escenario en diferentes espacios en los que los grupos de personajes hablan alternativamente. Tal y como dice el mismo Rubiera,

el aprovechamiento de este recurso tiene su momento más alto cuando una vez presentados todos los personajes necesarios para plantear el conflicto se les hace coincidir en un mismo espacio y se muestran diferentes áreas escénicas con las reacciones de los distintos grupos de actores. Es un modo muy efectivo de plasmar espacialmente el enredo dramático. ${ }^{15}$

En Primero es la honra que el gusto encontramos un uso bastante amplio de este recurso. De entre todos los ejemplos hemos de destacar una de las escenas de la primera

13 J. J. Pastor Comín, «La comedia de "enredo": Abrir el ojo, de Francisco de Rojas y El amor al uso, de Antonio de Solís. Análisis comparativo», EPOS, XV (1999), pp. 149-174.

${ }^{14}$ J. Rubiera Fernández, La construcción del espacio en la comedia española del Siglo de Oro, Madrid, Arco Libros, 2005, pp. 125-154.

15 Ibid., p. 143. 
jornada que se suceden en la casa de don Félix (vv. 419-468). En ella se presenta de manera paralela la concepción más espiritual del amor que mantienen los galanes y las damas frente a la visión más carnal de los criados:

\author{
Hermosísima Leonor, \\ ¡cómo haces cielo esta casa! \\ Templa empeños, que ya pasa \\ a ser exceso el favor. \\ No pródigo el resplandor \\ que en tu beldad se atesora \\ tanto madrugue, señora, \\ nuncio sea un arrebol, \\ que para que nazca el sol \\ sale primero la aurora. \\ Ese franco amanecer \\ de hermosa es desconfiar, \\ pues no, no para matar \\ toda tú te has menester: \\ el jazmín o el rosicler \\ vence en tus mejillas bellas \\ sin que fulmines centellas \\ de esos rayos superiores, \\ que si matas con las flores, \\ ¿para qué son las estrellas?
}

(vv. 419-438)

Pepino. Mientras se dicen los dos veinte y cuatro disparates, que fueran cuarenta y nueve si cupiera el asonante, nos podemos ir nosotros allí dentro a hacer aparte nuestros papeles, Florilla.

FLoRA. ¿No ve que es un ignorante Ero, vuesarced, mi rey, o mi Roque, pues no sabe que un pepino y una flor nunca traban maridaje?

Pepino. Anda, que eres una necia, no en flores el tiempo gastes, que, aunque el Papa no dispense, podrán en aqueste lance el pepino enflorecerse y la flor empepinarse.

(vv. 451-468)

Como se puede comprobar en este ejemplo la efectividad de la técnica es clara, pues la alternancia del discurso realza la distancia entre las dos concepciones del amor y, por tanto, aumenta el efecto cómico de las palabras de Pepino ${ }^{16}$.

${ }_{16}$ La comicidad en las palabras del gracioso reside en su procacidad, pues a través del juego lingüístico llevado a cabo mediante metáforas hortícolas con un trasfondo sexual deja claro cuáles son sus 
De la misma manera que el espacio se reduce, también hay una disminución del tiempo dramático. La acción de la comedia se desarrolla a lo largo de tres días, con lo que cada acto se corresponde, grosso modo, con un día en la historia de los personajes. Esta restricción temporal desemboca en la acumulación de enredos en un periodo relativamente corto de tiempo, fenómeno que, como dice Arellano ${ }^{17}$, «persigue un efecto de inverosimilitud ingeniosa y sorprendente, capaz de provocar la admiración y suspensión del auditorio», a la vez que induce a un mayor enmarañamiento de la intriga.

\section{JUEGOS DE OCULTACIÓN: LAS TAPADAS}

Unido irremediablemente a la reducción espacial encontramos el fenómeno de la ocultación, mediante el cual los personajes podrán esconderse para no verse inmersos en una situación comprometida o, en su caso, obtener una información valiosa en relación con sus intereses.

En un trabajo anterior hemos desarrollamos ampliamente aquellos casos en los que los personajes utilizan otras estancias y otras identidades para esconderse ${ }^{18}$. Por ello, en esta ocasión nos centraremos en un mecanismo del que gustaba mucho Rojas: las tapadas. Es un elemento recurrente en las comedias de capa y espada de nuestro autor y, como explica Serralta ${ }^{19}$, «no se debía naturalmente a ninguna obsesión por el disfraz ni a nada parecido, sino a la comodidad con la cual podía utilizar el autor una tapada para introducir confusiones o ignorancias de identidad, malentendidos y demás lances generadores de enredo».

Doña Ana aparece a mediados de la primera jornada tapada en casa de don Juan huyendo de un caballero (don Félix) del que debe guardarse. Pepino la acoge y la esconde en una de las estancias de la casa temiendo ser descubierto en el engaño: «Cuidado me da bien grande / esta tapada, yo temo / algún suceso de Marte» (vv. 558-560).

intenciones con la criada. Para profundizar más en este tema véase J. Matas Caballero, «Erotismo en el teatro de Rojas Zorrilla. I. La risa erótica», Lectura y signo, 3 (2008), pp. 271-308.

17 I. Arellano, «La comedia de capa y espada. Convenciones y rasgos genéricos», Cuadernos de teatro clásico, 1 (1988), recogido en Convención y recepción. Estudios sobre el teatro de Siglo de Oro, Madrid, Gredos, 1999, p. 45.

18 A. Gutiérrez Gil, “Juegos de identidad y ocultación en Primero es la honra que el gusto de Rojas Zorrilla”, en $\mathrm{M}^{\mathrm{a}}$ Luisa Lobato (coord.), Máscaras y juegos de identidad en el teatro español del Siglo de Oro, Madrid, Visor Libros, 2011, pp. 475-488

19 F. Serralta, “El enredo y la comedia: deslinde preliminar", Criticón, 42 (1988), p. 132. 
Desde la habitación en la que se encuentra agazapada escucha cómo don Rodrigo quiere casar a su hija con don Juan, su amado. Ante tal noticia no puede contener su ira, pues conllevaría perderlo. Así dice: «iAy, don Juan! No has de casarte / aunque me cueste la vida» (vv. 660-661).

Una vez que se cree sola, todavía tapada, doña Ana sale de su escondite. Sin aviso alguno se topa con don Félix, quien la confunde con Leonor:

Va a salir doña Ana y entra don Félix y piensa que es Leonor.

Don FÉLIX. (Logre la suerte crueldades en quien...) Señora, mi bien.

LEONOR. (¡Que esto escuche!)

DON FÉlix. No recates

esas estrellas, que al sol...

Aguarda, espera, no pases.

(vv. 661-666)

Leonor está observando toda la escena desde otra estancia y al creer ver que su amado corteja a otra mujer sale enfurecida de su escondite, tal y como reza la acotación: Éntrase doña Ana. Don Félix quiere ir siguiéndola y, al entrarse, le detiene Leonor muy enojada (v. 666). El hecho de que doña Ana se encontrase tapada complica de manera involuntaria el enredo y obstaculiza la relación entre don Félix y Leonor.

En el tercer acto las damas vuelven a protagonizar un episodio que se fundamenta en el recurso de la tapada. En este caso buscan el engaño de manera voluntaria para alcanzar sus fines. Don Juan ha mantenido a lo largo de toda la obra una ambigüedad por la cual corteja a doña Ana mientras que se sabe prometido con Leonor. Así, las damas deciden desenmascararlo y restablecer el orden en sus relaciones:

[DoÑa Ana] Pero aquí viene don Juan; quiero que me halle tapada por ver si me desconoce de la suerte que me habla.

Sale don Juan y piensa que es Leonor doña Ana.

Don JuAn. Leonor mía, ¿pero cómo con manto sales de casa? ¿No respondes? ¿Qué accidente te enmudece y acobarda?

Doña Ana. ¿A dónde vas?

Don Juan. (iAy de mí, fortuna airada!)

Antes vengo. Descúbrese.

Pues, ¿cómo...

DoÑA ANA. puesto que con vos no bastan Pues, jvive el cielo!, ni cautelas prevenidas, ni finezas declaradas, 


$\begin{array}{ll} & \text { para que reverenciéis } \\ & \begin{array}{l}\text { de mi decoro las aras } \\ \text { que a la obstinada violencia } \\ \text { de mis... }\end{array} \\ \text { DON JUAN. } & \end{array}$

Sale Leonor.

LEONOR. Advertid, señor don Juan, que es conmigo la batalla y que es mía la razón; prevenid valientes armas.

DON JUAN. ¡Fuerte lance!

LEONOR. Oídme atento.

Doña Ana. Hoy mi vida se restaura.

(vv. 1753-1776)

Mediante esta trampa consiguen enredar más la trama y complicar el desenlace, manteniendo al público intrigado hasta el último momento.

Tanto el recurso de las tapadas como el resto de mecanismos de ocultación hilvanan toda la obra y son los encargados de añadir más ramas al tronco de la acción. De hecho, si subdividimos los cuadros en las escenas que los componen, del total de treinta y tres escenas que articulan la obra, ocho se basan en juegos de ocultación, lo que se traduce en un $25 \%$ del total, porcentaje que avala la importancia de este componente del enredo para el devenir de la historia.

\section{ESCENAS NOCTURNAS}

Además de jugar en la historia con puertas, cortinas, ropas o máscaras para introducir equívocos entre los personajes, Rojas gustaba de incorporar escenas nocturnas en las que unos caracteres dialogan con otros sin poder constatar su verdadera identidad incurriendo, por lo tanto, en crasos errores que marcarán su rol a lo largo de la historia.

Dentro del corpus del toledano encontramos numerosos ejemplos: desde el paradigmático caso de Entre bobos anda el juego en el que los personajes establecen relaciones cruzadas en la oscuridad que ofrece el interior de la posada a Donde hay agravios no hay celos, donde amo y criado intervienen en una lid en el interior de una estancia intercambiando sus identidades bajo el amparo de la falta de luz.

Dentro de esta tipología de escenas nocturnas hemos de reparar en aquellas en las que los personajes utilizan la oscuridad para esconderse y evitar el encuentro con alguien no deseado: 
Cualquier ruido en la noche despierta la duda y en seguida se intenta descubrir si hay algún intruso. Se traen y llevan luces, se registran los aposentos, mientras el amante huye o se esconde. [...] De nuevo, para evitar cualquier encuentro o inconveniente, la rapidez en el escondite es primordial. ${ }^{20}$

Este es el caso de Primero es la honra que el gusto. Tras la aparición repentina de Pepino en circunstancias poco razonables en casa de Leonor, don Rodrigo, una vez llega la noche, decide inspeccionar la casa a la luz de una vela y comprobar que no hay nadie en ella. Al llegar a una puerta escucha cómo alguien llama desde dentro. De nuevo se enreda la historia y la oscuridad se erige como el mejor contexto de una escena llena de comicidad:

Tienta la puerta y en el ruido que ha de hacer un pestillo parezca que está cerrada. Va a pasar a la otra y llama don Juan por de dentro.

DON JUAN. ¿Es Leonor?

Don Rodrigo. (¡Ay de mí! ¡Terrible pena!)

Don FÉlix. (¿Qué escucho? ¡Ah tirana, cómo

fueron mis sospechas ciertas!)

DON JUAN. Abre, mi bien.

Don Rodrigo. (iQue al combate

de esta desdicha no muera!

No está en la puerta la llave, abriré con la maestra.)

Sí, yo abro.

Sale don Juan y túrbase.

DON Juan. ¡Oh, Leonor mía!

(Mas, ¿qué miro? ¡Fuerte fiera!)

(vv. 1325-1334)

Aprovechando que Leonor había escondido allí a don Juan para encontrarse con él más tarde, don Félix ocupa el lugar que ha dejado vacío su contrario. Al momento aparece Leonor con una luz, tal y como reza la acotación: Escóndese don Félix donde estaba don Juan y sale Leonor con luz (v. 1436+). De nuevo, la oscuridad le hace un flaco favor a la dama y es descubierta en el engaño:

Ya parece que mi padre en mansa quietud sosiega.

Segura, pues, a don Juan podré hablar. Llego a la puerta. Don Juan, bien podéis salir.

Mas, ¿qué veo? ¡Pena inmensa!

(vv. 1437-1442)

Como comprobamos en las escenas en las que se encuadran los ejemplos expuestos en este apartado, la oscuridad no solo es una aliada perfecta para poder

20 J. Rubiera Fernández, op. cit, 2005, p. 161. 
escapar en una situación comprometida, sino que permite a los personajes conocer de primera mano información muy valiosa en el devenir de los acontecimientos a la que, de otra manera, no podrían tener acceso. El resultado final de estas situaciones en el corral es la carcajada en el espectador, pues están plasmadas por Rojas con tal habilidad en el manejo escénico que hacen partícipe al público del ridículo que sufren unos personajes frente a otros.

\section{LOS CELOS}

El último de los componentes del enredo que queremos exponer son los celos, procedentes de los intereses amorosos cruzados que se presentan en Primero es la honra que el gusto. Estos aparecen como consecuencia de diferentes equívocos entre los personajes y de la distorsión de ciertas informaciones.

Las víctimas principales de los celos son don Félix y Leonor, que a lo largo de la primera y la segunda jornada se ven arrastrados a un juego de desconfianzas que consigue minar la estabilidad de su amor.

En la mayoría de las ocasiones en las que aparecen lo hacen engarzados con otro componente del enredo al que ya hemos hecho referencia: la ocultación. Ya sea por el desconocimiento o la distorsión de una información, ya sea por la confusión de identidades, a los personajes les invaden unos celos incontrolables. Veamos algunos ejemplos.

Al comienzo de la primera jornada don Félix recibe la carta de una antigua amante suya de Sevilla llamada Violante. Como sus intenciones están dirigidas hacia Leonor hace caso omiso de la misiva y la rompe en pedazos. Flora, que ve la escena escondida al paño, recoge los pedazos y entrega la carta a su señora. Se despierta en Leonor el recelo y desconfía de los halagos que le profiere el caballero:

Señor don Félix, templad
hipérboles, que es muy tarde
para prevenir remedios
a tan peligroso achaque.
Yo he sabido ya que sois
tan abonado tratante
en empleos amorosos
que, porque jamás no falte
correspondencia tenéis
- resguardo importante y fácil-
en Madrid una Leonor
y en Sevilla una Violante.

(vv. 483-494) 
Continuando con los celos que la existencia de esta dama sevillana despierta en Leonor, al final de la primera jornada asiste a la conversación que don Félix, por equivocación, mantiene con doña Ana (que aparece tapada). Creyendo que la dama es Violante, Leonor vuelve a increpar al galán y el curso de su relación queda momentáneamente desviado:

\begin{tabular}{|c|c|}
\hline Don FÉLIX. & $\begin{array}{l}\text { ¡Que esto me suceda, cielos! } \\
\text { ¿Qué mujer pudo ocultarse? } \\
\text { ¿Cuándo? ¿Cómo? Estoy sin juicio. }\end{array}$ \\
\hline LEONOR. & $\begin{array}{l}\text { Pues no le perdáis, cobradle, } \\
\text { que no importa que esté oculta } \\
\text { en vuestra casa Violante, } \\
\text { que no es mal huésped, don Félix. }\end{array}$ \\
\hline
\end{tabular}
(vv. 695-701)

Sin embargo, a partir de la segunda jornada la moneda muestra su otra cara y es don Félix quien comienza a sufrir los efectos de los celos, pues don Juan, bajo el amparo del padre de la dama, comienza su cortejo abiertamente. Más aún, le pide consejo a don Félix, gota que colma el vaso de su paciencia: «Don Félix: (Rabiando voy a morir) / FLORA: (Chispeando de celos va)» (vv. 945-946).

Informada por su criada, a partir de este momento la finalidad primera de Leonor será templar los celos de don Félix, unos celos basados en falsas apariencias que no se corresponden con la realidad:

$$
\begin{aligned}
& \text { Oye, pues, los desengaños } \\
& \text { de tus celos porque adviertas } \\
& \text { que no es legítimo el juicio } \\
& \text { que de apariencias se engendra. }
\end{aligned}
$$

Estos celos que dominan el proceder de damas y galanes se disiparán en el transcurso de la tercera jornada. Leonor, tras una extensa conversación con doña Ana, ve cómo sus desconfianzas estaban construidas sobre cimientos poco sólidos, pues ve claro que la dama no intenta conseguir el amor de don Félix, sino el de don Juan. Por su parte, don Félix comprende que la boda de Leonor con don Juan había sido una imposición paterna, lo que hace desaparecer las dudas sobre la sinceridad de los sentimientos de su amada. De tal manera, confiesa a don Rodrigo el amor que siente hacia su hija y le pide su mano, que es gustosamente concedida. Consecuentemente, el caballero consigue restaurar la paz y el orden entre todos los personajes implicados en el enredo.

\section{CONCLUSIÓN}

Después del análisis de los diferentes componentes del enredo en Primero es la honra que el gusto, queda claro que pasan a ser los pilares sobre los que se sustenta 
la historia y, por tanto, la comedia. Sin los juegos de ocultación, la inclusión de escenas nocturnas o la reducción del tiempo y del espacio la historia carecería de interés dramático y perdería toda su comicidad; sin la aparición de los celos los personajes no serían capaces de participar en trampas que, finalmente, les conducen a una ridiculización que se traduce en nuevos lances cómicos; y sin la interesada intervención de Flora podríamos decir que desaparecería el principal combustible que hace funcionar la máquina del enredo.

En todas las clasificaciones tipológicas en torno al corpus dramático de Francisco de Rojas Zorrilla Primero es la honra que el gusto ha sido considerada dentro del grupo de las comedias de capa y espada, tanto por la temática amorosa como por el tipo de personajes que la protagonizan. Además, como hemos constatado, se pueden rastrear otros tres elementos que Arellano ${ }^{21}$ añadía a la definición del género: la reducción temporal, la reducción espacial y la reducción en el elenco de personajes.

Sin embargo, si enfocamos la definición hacia los componentes del enredo podríamos decir que estamos ante una comedia de enredo. Muchos críticos hacen equivalentes ambas etiquetas; otros consideran que la comedia de enredo es una evolución de la comedia de capa y espada ${ }^{22}$. Frédéric Serralta ${ }^{23}$ señalaba el punto de arranque de este tipo de comedia «cuando el enredo pasó a ser, no solo el esqueleto, sino la carne y la sangre, $[. .$.$] no solo el «cómo» sino el «qué» de muchas comedias auriseculares».$

En este caso los recursos del enredo gozan de vital importancia para el desarrollo de la acción, y podríamos llegar a decir que son el «cómo» al que hace referencia Serralta; sin embargo estaríamos pasando por alto la verdadera problemática que se trata en la obra y que se convertiría en el corazón que bombea la «sangre» (siguiendo con la metáfora del crítico citado): la libertad de la mujer para escoger su propio marido.

Debido a esto, y siguiendo la etiqueta que ha identificado a este tipo de obra dramática a lo largo de los siglos, continuaremos definiendo a Primero es la honra que el gusto como una comedia de capa y espada en la que los componentes del enredo juegan un papel indispensable en el transcurso de la acción dramática.

\footnotetext{
${ }_{21}$ I. Arellano, op. cit., 1999, pp. 37-69.

22 «En las preceptivas al uso se habla de «enredo» como la parte de la comedia en la que se complican los lances, pero no como un género determinado de la comedia. Este género, como definió Serralta, se forja con el tiempo, cuando la demanda teatral es tan elevada que la creación dramática se convierte en un producto de consumo y se mecaniza el arte de escribir comedias. En ese momento aparecen unas comedias cuya existencia se justifica únicamente por crear situaciones enredadas, en las que se engazan diversos episodios a través de una serie de mecanismos que se automatizan» (T. Julio, «La ocultación en la comedia de enredo de Rojas Zorrilla», en Felipe B. Pedraza Jiménez y Rafael González Cañal (eds.), La comedia de enredo. Actas de las XX Jornadas de teatro clásico. Almagro, 8, 9 y 10 de julio de 1997, Almagro, Universidad de Castilla-La Mancha-Festival de Almagro, 1998, p. 238).
}

23 F. Serralta, op. cit., 1988, pp. 129-130. 